\title{
UM MAPEAMENTO DAS APROXIMAÇÕES ENTRE Weber e NieTzSCHE
}

\author{
A MAPPING OF SIMILARITIES BETWEEN WEBER AND NIETZSCHE
}

\author{
Leandro dos Santos ${ }^{\mathrm{a}}$
}

\begin{abstract}
Resumo Este artigo tem por objetivo um levantamento dos principais tópicos de aproximação entre a Sociologia de Max Weber (1864-1920) e a Filosofia de Friedrich W. Nietzsche (1844-1900). Para tanto, sublinharam-se os pontos mais expressivos e correntemente observados na literatura acerca das aproximações entre Weber e Nietzsche. Nesse sentido, os traços de maior afinidade foram encontrados nos seguintes temas: poder, conhecimento, modernidade e ética.
\end{abstract}

Palavras-chave Max Weber; F. Nietzsche; Sociologia alemã.

Abstract This article aims to survey the main points of contact between the Sociology of Max Weber (1864-1920) and the Philosophy of Friedrich W. Nietzsche (1844190o). Therefore, we emphasize the most expressive and commonly observed points in the literature dealing with the similarities between Weber and Nietzsche. In this sense, the traits that show higher affinity were found in the following topics: power, knowledge, ethics, and modernity.

Keywords Max Weber; F. Nietzsche; German Sociology.

A ideia de um mapeamento das aproximações entre Weber e Nietzsche tem por objetivo realizar um levantamento dos tópicos de maior relevância no que se refere a essa articulação. Para tanto, realizar-se-á um esforço de apresentação que sintetiza o estado da arte no campo de comentadores especializados na discussão sobre a afinidade entre os dois autores alemães. Com isso, espera-se contribuir com um delineamento amplo e conciso dos temas fundamentais presentes na reflexão sobre as afinidades temáticas entre Weber e Nietzsche.

a Mestre em Sociologia Política e doutorando no Programa de Pós-Graduação em Sociologia Política - UFSC. 
No que segue, começar-se-á por uma introdução, em que se apresentam sumariamente a recepção weberiana do pensamento de Nietzsche e um panorama sobre o campo da literatura dos comentadores que exploraram a relação entre os dois autores. Na sequência, agrupam-se os tópicos de maior relevância e recorrência no que se refere às ligações entre Weber e Nietzsche, traçadas a partir de uma pesquisa sobre essa literatura especializada. Como resultado, foi possível destacar quatro grandes temas de aproximação: a) a questão do poder; b) considerações epistemológicas; c) apreensão da modernidade; e d) postura ética ou posicionamento diante do mundo.

No decurso desta pesquisa bibliográfica, observou-se que o elo fundamental que liga o pensamento de Weber ao encontro da Filosofia nietzschiana é a questão dos valores culturais. Aqui se articulam todos os quatro eixos estruturantes expostos. É a questão dos valores que fará com que Weber reflita sobre os conflitos e as divergências no seio da vida social, construa sua metodologia e o alcance do conhecimento científico e, por fim, formule o diagnóstico do "desencantamento do mundo" e a resposta individual a este mundo moderno.

\title{
INTRODUÇÃO
}

Uma estimativa sobre a consideração pessoal de Weber em relação à relevância do pensamento nietzschiano no ambiente intelectual de seu tempo pode ser avaliada em um de seus comentários, poucas semanas antes de sua morte. Em fevereiro de 1920, Weber assim se referiu ao peso das contribuições de Nietzsche, bem como de Marx:

\begin{abstract}
A honestidade de um intelectual atual, sobretudo de um filósofo atual, pode ser medida por sua atitude com respeito a Nietzsche e Marx. Quem quer que não admita que partes consideráveis de seu próprio trabalho não poderiam ter sido realizadas sem o trabalho desses dois apenas engana a si mesmo e aos outros. $\mathrm{O}$ mundo que espiritualmente e intelectualmente vivenciamos hoje é um mundo substancialmente modelado por Nietzsche e Marx (HENNIs, 1986, p. 181).
\end{abstract}

Do exposto, ainda que a título indicativo, percebe-se a considerável importância que Weber conferia ao pensamento de Nietzsche, bem como ao de Marx. É de se esperar que, diante de uma declaração dessa envergadura, o próprio Weber tenha considerado, ao menos relativamente, seu trabalho à luz das considerações de Nietzsche e Marx. De fato, a vida intelectual alemã, no período em que Weber 
se situa, em função de suas convicções, era fortemente influenciada por Marx e Nietzsche. Na evolução de sua obra, Weber procurou fazer frente à concepção unilateral da história presente na tese materialista quanto aos condicionamentos econômicos dos processos sociais, de modo que o debate travado com Marx ou com o marxismo é facilmente observável. Já a relação com o pensamento nietzschiano se torna uma "presa esquiva” ao leitor que queira demarcar tal aproximação, ainda mais prejudicada por uma imagem posteriormente atribuída a Weber enquanto homem puro e inteiramente dedicado à ciência, democrata e liberal (FLEISCHMANN, 1977).

Em lugar de um condicionamento unilateral dos fenômenos históricos, Weber concluiu por um condicionamento recíproco entre os fatores econômicos e culturais. E é justamente nessa dimensão da cultura que está a chave para entender a presença da filosofia de Nietzsche em sua obra e, mais especialmente, de seus últimos trabalhos. Aqui assume importância a questão dos valores morais, da carga idiossincrática e contingente de tais valores, o que faz desaguar no caráter plural e agonístico da cultura na trama das relações sociais.

Nessa época, que transcorre nos fins do século 19, a influência de Nietzsche no campo intelectual alemão já era acentuada, e os sociólogos que provinham quase todos da Filosofia o haviam descoberto muito cedo. A recepção weberiana e a imagem que o sociólogo construiu acerca do pensamento de Nietzsche se devem muito à interlocução com dois de seus contemporâneos e amigos pessoais, Ernst Troeltsch e Georg Simmel.

Para Troeltsch, foi Nietzsche quem primeiro se insurgiu de maneira bem-sucedida contra a concepção dos valores metafísicos, morais ou religiosos, enquanto entidades absolutas e esvaziadas do conteúdo humano, demasiadamente humano. Nietzsche abriu caminho para uma compreensão mais empírica e sociológica dos valores culturais, enraizando-os no contexto humano da criatividade, força e ação. Aos olhos de Troeltsch, "foi mérito incontestável de Nietzsche ter transformado a teoria da vontade de Shopenhauer em uma teoria que torna compreensíveis os fenômenos sociais a partir do indivíduo forte” (Fleischmann, 1977, p. 170).

A relação entre Simmel e Weber, de amplo reconhecimento, é também determinante na leitura weberiana de Nietzsche. A esse respeito, é testemunho marcante o exemplar com anotações de Weber às margens do livro Shopenhauer e Nietzsche (1907), escrito por Simmel. Nessa escrita, a Filosofia de Nietzsche se apresenta como uma revolução no campo da moral, assentada em uma rejeição dos princípios de altruísmo, piedade e de qualquer sombra valorativa em que possa se abrigar "confortavelmente" o espírito ou o comportamento mediano da 
massa. Qualquer indício da moral utilitária ou de rebanho é visto como sintoma de decadência, uma vez que exalta a mediocridade - aqui a dignidade do gênero humano reside na força das realizações individuais, no exercício de impor seus próprios valores. Mais uma vez, retoma-se a ideia de que o pensamento nietzschiano forneceria a chave para compreender de forma concreta a formação dos valores culturais, o que remete às personalidades fortes, na imposição da vontade de poder, e às estruturas de dominação na sociedade.

Em suma, na leitura da filosofia nietzschiana que gravita em torno das figuras mais caras a Weber, Simmel e Troeltsch, os termos como indivíduo, força, ação e valores são bastante destacáveis e demonstram a linha interpretativa e, além disso, operativa com que Weber incorpora em seu próprio pensamento. Essa captura de uma espécie de "nietzscheísmo político" difere, portanto, de um "nietzscheísmo poético" presente no movimento literário encabeçado por Stefan George (FLEISCHMANN, 1977). A questão nuclear dessa leitura mais dura de Nietzsche era a concepção dos valores culturais enquanto manifestações concretas do poder e circunscritas à arbitrariedade própria que se inscreve nas individualidades históricas.

Na obra de Weber é possível verificar passagens textuais que, de maneira mais ou menos explícita, apontam para o pensamento nietzschiano - que a seguir apenas pontua-se com dois exemplos. Ainda que sejam raras as referências a qualquer que seja o autor nos textos weberianos, pode-se demonstrar, por exemplo, menção direta a Nietzsche, em Introdução à ética econômica das religiões mundiais, escrita em 1913. Aqui o sociólogo observa que uma "determinação de classe, bastante geral e abstrata, da ética religiosa poderá ser deduzida da teoria do 'ressentimento', conhecida desde o brilhante ensaio de Friedrich Nietzsche" (WEBER, 1982, p. 313).

Em outras passagens, a recepção da obra nietzschiana se apresenta de forma mais latente, com a utilização de expressões, mas sem a referência direta ao autor. Como ilustração, aparece no fechamento de Ética protestante, originariamente escrita no período de 1904-1905, quando Weber escreve: "então, para os 'últimos homens' desse desenvolvimento cultural, bem poderiam tornar-se verdadeiras as palavras [...]", trecho que se completa com o famoso registro das ameaças à condição humana no desenvolvimento do espírito capitalista: "especialistas sem espírito e gozadores sem coração" (WEBER, 2004, p. 166). Aqui a expressão “últimos homens" deriva de Nietzsche, que a utiliza, por exemplo, na crítica que faz à ideia de felicidade das modernas sociedades capitalistas.

No contexto da literatura de comentadores, não há uma extensa produção acerca das conexões e proximidades entre Weber e Nietzsche, sendo a contribuição 
de alguns poucos textos de fundamental importância à introdução nesse debate. Nas últimas décadas, assistiu-se a um considerável aumento de estudos sobre o pensamento de Nietzsche. O desenvolvimento dessa literatura especializada sobre as relações entre Weber e Nietzsche no contexto internacional pode ser ilustrado, muito didaticamente, por meio de uma periodização. Para tanto, seguiu-se de perto o esquema descrito por Öelze (2000), em que se apresentam quatro etapas desse desenvolvimento.

Na primeira fase repousaria uma compreensão, ainda que velada, da recepção weberiana de Nietzsche, ou seja, haveria o entendimento dos traços nietzschianos em Weber, mas que não foi devidamente sistematizada em uma exposição pública nos trabalhos daquela geração. Nessa fase que se estenderia até 1933, figurariam autores como Karl Löwith, Siegfried Landshut e Thomas Mann.

A segunda fase, que se estenderia de 1959 a 1965, inauguraria a exposição claramente tematizada sobre a relação Weber e Nietzsche. Essa etapa é fundamentalmente balizada pelo texto seminal de Eugène Fleischmann, intitulado De Weber a Nietzsche, de 1964. Esse texto ainda se constitui como o trabalho que apresenta mais vastamente os tópicos de aproximação entre Weber e Nietzsche, referência indispensável no debate em questão.

Da terceira fase em diante, que se estende de 1982 a 1989, a questão sobre as relações entre Weber e Nietzsche adquiria maior expressão em termos quantitativos. Destaca-se, nesse período, principalmente o livro Max Webers Fragestellung [A questão de Max Weber], de Wilhelm Hennis, também destacada referência nesse campo, onde consta mais especificamente o capítulo intitulado "Die Spuren Nietzsche im Werk Max Webers" ["Os traços de Nietzsche no trabalho de Max Weber"]. Outras expressões desse período seriam duas obras de Robert Eden, Bad conscience for a Nietzschean age: Weber's calling for science [Má consciência de uma era nietzschiana: o chamado de Weber à ciência], de 1983, e Political leardership and nihilism: a study of Weber and Nietzsche [Liderança política e nülismo: um estudo de Weber e Nietzsche], de 1984.

Gabriel Cohn, situando-se no intervalo entre a segunda e a terceira fase, inaugura a discussão sobre o assunto no Brasil, apresentando, no livro Crítica e resignação, de 1979, o capítulo “Weber, Nietzsche e a crítica dos valores”. A partir da década de 1980, adentrar-se-ia, conforme sugestão de Öelze, na quarta etapa dos estudos sobre as relações entre Weber e Nietzsche, fase essa em que se elabora uma análise mais aprofundada sobre temas específicos de aproximação.

Uma nota importante surge da constatação de que, desde a terceira fase no desenvolvimento da literatura de comentadores, a questão da influência nietzs- 
chiana sobre Weber tornou-se marginal, não constituindo uma preocupação dos estudos mais recentes. Desde então, uma abordagem comparativa entre os dois autores alemães é o que mais marcadamente caracteriza os trabalhos de análise. Aliás, sobre isso, é possível identificar algumas diferenças no posicionamento dos comentadores acerca das relações entre Weber e Nietzsche.

\section{A QUESTÃO DO PODER NA VIDA SOCIAL}

Em seu artigo De Weber a Nietzsche, Fleischmann esforça-se em delinear os traços nietzscheanos presentes na obra de Weber. Com esse trabalho de inaugural sistematização sobre as relações entre Weber e Nietzsche, o autor praticamente alicerça os fundamentos da literatura e os debates posteriores em torno das proximidades entre os dois intelectuais alemães. Como enfatiza, "Weber é também um dos sociólogos que não hesitaram em trabalhar à luz das hipóteses nietzscheanas" (Fleischmann, 1977, p. 178). Uma das clareiras iluminadas - entre outras - pelas hipóteses nietzschianas e de grande impacto na obra weberiana se configura no desenvolvimento de um projeto de "Sociologia da dominação". Na última fase da Sociologia geral de Weber, a questão do poder apresenta-se como um centro de gravidade. Segundo Fleischmann, Weber teria aceitado uma indicação de Nietzsche de que queria no "lugar da 'Sociologia', uma doutrina das configurações de domínio" (NieTzsche, 2008, p. 249). Nesse sentido, Weber teria dado execução ao plano, na medida em que buscava "apreender as relações de dominação que se escondem por trás da hierarquia de valores existente em uma sociedade dada" (NIETZSCHE, 2008, p. 181-182).

Fleischmann sustenta que a questão do poder se apresenta como chave de entendimento de algumas importantes seções da obra weberiana, notadamente encontradas na Sociologia da religião e da política. No que se refere aos estudos da religião, essa "não deixa de ser um dos domínios possíveis do exercício do poder do homem sobre o homem e que ela é, por conseguinte, [...] uma subseção da 'grande' Sociologia da dominação" (NiETzSche, 2008, p. 181).

Sobre o campo propriamente político, a questão do poder fica ainda mais evidente. Nessa dimensão, Weber introduz categorias do pensamento nietzschiano em torno do poder que, no filósofo, remetem para muito além das fronteiras do campo político. Como exemplo, citam-se a utilização dos conceitos de "vontade de poder" e a noção de um "novo homem" (o "além-do-homem" nietzschiano). A atenção weberiana pela política prática (a "pequena política", nos termos nietzschianos) é notadamente uma das grandes marcas que diferenciam os pensadores. 
A concepção weberiana da política, que também se estende à sua Sociologia geral, é essencialmente marcada pelos elementos de poder e dominação. Acerca de um discurso de Weber em Friburgo (1895), Fleischmann aponta como o pensamento weberiano se desenvolve em torno das ideias de poder e dominação. Nesse discurso, estariam afirmações tais como: a "vontade de poder e de dominação não é somente privilégio do estadista, ela também está no centro da vida econômica" e "toda a civilização nada mais é do que uma luta pela vida, onde os mais viáveis prevalecem e dominam" (Fleischmann, 1977, p. 156).

Essa imagem do mundo como uma configuração de forças, embate de vontades, é um relevante ponto de contato entre Weber e Nietzsche. Como atesta Renarde Freire Nobre (2004, p. 35), a "afinidade pelo reconhecimento da cultura e da vida como campos de domínio e de luta é, sem dúvida, um ponto forte na relação entre Weber e Nietzsche". Essa visão traz também em seu bojo o compartilhamento de dois pressupostos fundamentais: o caráter perspectivista e agonístico da cultura e da vida.

O caráter perspectivista consiste na "idéia de que as ações e vivências humanas possuem sentimentos múltiplos em cuja singularidade são irredutíveis umas às outras, expressando finalidades últimas incondicionais ou irracionais" (NOBRE, 2003, p. 54). O perspectivismo no seio da vida social se expressa na forma de uma subjetividade última dos valores que motivam a ação humana e conferem sentido à existência. Esses valores como fins não seriam produtos de um processo inteiramente racional, mas expressões que respondem a motivações irracionais.

Diante de um universo social em que os valores culturais manifestam-se por meio de perspectivas, isto é, de escolhas subjetivas, impõe-se o segundo pressuposto compartilhado por ambos os autores: o caráter agonístico, entendido como o conflito entre as diferenças de vontade e perspectivas. Para que se faça valer determinados valores, torna-se necessário afirmá-los em um campo de disputa em que se encontram outras perspectivas de valores, outras vontades de poder que entram em cena para impor seus significados. Para ambos, o "curso de uma ação ou o fluxo de uma força só se efetiva sob tensão com outros cursos possíveis" (NOBRE, 2003, p. 57).

Dado que as perspectivas valorativas buscam por sua efetivação na dinâmica da vida social, estas só podem se estabelecer no decurso de relações de confrontação, de embate, uma vez que "tudo que se efetiva indispõem-se e luta" (NoBre, 2003, p. 57). Diante de uma visão geral sobre o processo de construção de valores na dinâmica vida social, compartilhada por Weber e Nietzsche, é que se torna relevante uma atenção sistematicamente dirigida às relações de poder e conflito. 


\section{CONSIDERAÇÕES EPISTEMOLÓGICAS}

Entre os temas destacáveis na relação entre Weber e Nietzsche, não haveria exagero em dizer que a mais recorrentemente enfatizada na literatura especializada gira em torno das considerações de cunho epistemológico e dos procedimentos metodológicos.

Como visto anteriormente, Weber e Nietzsche compartilham o pressuposto de que os valores na vida social são questões de perspectiva, valorações específicas que entram em conflito na busca por sua efetivação na vida social ou mesmo na vida em geral. A fim de abarcar reflexivamente tal "pluralismo de valores", torna-se necessário, para tanto, um método apropriado que dê conta da tarefa. Nessa direção é que se observa uma forte afinidade entre a elaboração weberiana dos "tipos ideais" com o "perspectivismo" nietzschiano. E, conforme expresso por Otávio Velho, essa proximidade não seria "de pouca importância, pois é por aí que ambos relativizam as totalidades e os cursos definidos da história” (Velho, 1995, p. 89-90).

Na terceira dissertação da Genealogia da moral, Nietzsche apresenta a concepção perspectivista como um método de conhecimento da realidade: "Existe apenas uma visão perspectiva, apenas um 'conhecer' perspectivo; e quanto mais afetos permitirmos falar sobre uma coisa, quanto mais olhos, diferentes olhos, soubermos utilizar para essa coisa, tanto mais completo será nosso 'conceito' dela, nossa 'objetividade'” (NieTzsche, 1998, p. 109). Na mesma direção, a construção dos tipos ideais em Weber corresponderia a um procedimento metodológico diante de um universo plural de ações e valores. Conforme entendimento de Nobre (2003, p. 55), a "tipificação" significaria "uma confirmação de que todo conhecimento parte de um ponto de vista particular", e a "ideação", "uma confirmação de que a objetividade (ou a pureza lógica) não é uma propriedade da realidade mas, sim, da representação teórica".

Fleischmann observa, quanto aos tipos ideais, que essa elaboração metodológica se aproxima da filosofia dos valores de Nietzsche. A crítica nietzschiana dos valores aponta para a precariedade das pretensões de determinação da "verdade", sejam quais forem: filosóficas, positivistas, religiosas ou morais. Segundo aponta Fleischmann, o elemento de contato entre a Filosofia weberiana da ciência com a crítica nietzschiana dos valores seria o elemento da arbitrariedade dos valores, isto é, de seu caráter perspectivista. Desse modo, indo ao encontro do questionamento sobre o caráter normativo e transcendente dos valores, Weber, "que jamais 
teve ilusões sobre o caráter subjetivo, arbitrário, 'demasiado humano' dos valores, coloca-se visivelmente do lado de Nietzsche" (Fleischmann, 1977, p. 144).

Ainda em torno dos valores, Otávio Velho faz ver também uma relação dos "tipos ideais" com a crítica nietzschiana da linguagem. Em ambos os casos, o que estaria em jogo seria o entendimento de que o mundo, o mundo mesmo, não se reduz às malhas da linguagem. $\mathrm{O}$ tipo ideal parece enquadrar-se na discussão de Nietzsche sobre a linguagem, na medida em que as considera como uma "utopia (não é 'verdadeiro'), inevitável e extremado” (VelHo, 1995, p. 82).

Fleischmann sustenta que Weber teria mantido a compreensão de "que tudo o que podemos conhecer cientificamente a respeito da realidade humana são justamente essas sínteses históricas parciais construídas de acordo com as regras da causalidade em torno de um tipo “ideal”' (Fleischmann, 1977, p. 144). Por um lado, a questão sobre a margem de parcialidade e precariedade contida nas possibilidades do conhecimento sobre a realidade aproxima a construção weberiana dos tipos ideias com a postura perspectivista de Nietzsche. Por outro, Weber, como cientista, ainda se importa com a questão da veracidade. Como sugere Cohn, em um primeiro momento, Weber compartilharia com Nietzsche a visão de que existem múltiplas histórias possíveis de serem interpretadas, "falar de uma história ou de outra é uma questão de 'perspectiva', de interpretação" (CоHN, 1979, p. 107). No entanto, sustenta o comentador, Weber não se despede de uma busca pela veracidade, que somente é atingida e tornada válida por meio do método científico. Embora exista a possibilidade de múltiplas reconstruções histórias, já que assentadas a partir de uma perspectiva, Weber jamais chegaria "ao ponto de negar a idéia de que se possa alcançar uma verdade científica a respeito da história e da sociedade, ainda que particularizada" (CoHN, 1979, p. 107).

Para que a construção dos tipos ideais seja um tipo de conhecimento válido, Weber procurou assentar tal construto ideal no domínio empírico dos acontecimentos históricos e segundo as regras da causalidade. Segundo Fleischmann (1977, p. 148), isso quer "dizer que o 'tipo ideal' continua pura ficção na medida em que não seja confrontado com o desenrolar real - isto é, causal - dos acontecimentos".

Tal verdade poderia ser assegurada uma vez que a "exigência da análise causal prende o pesquisador às regras universalmente aceitas do método científico, e assegura o caráter também universal das suas conclusões" (CoHN, 1979, p. 110). A procura em se sustentar a produção de uma verdade a partir da análise das causalidades históricas e da sua verificação empírica sinaliza um dos traços de afastamento de Weber em relação a Nietzsche. Nesse sentido, segundo Cohn, Weber não iria tão longe quanto Nietzsche na crítica do "substancialismo" do 
conhecimento, ou seja, das pretensões de se atingir pelo intelecto "verdades essenciais". Ainda que a operacionalização dos tipos ideais compartilhe os traços com a epistemologia perspectivista de Nietzsche, a necessidade de evidências empíricas e conexões causais faria Weber, nesse quesito, afastar-se da posição nietzschiana. Dessa maneira, Weber estaria como que se movendo "exatamente dentro do universo que Nietzsche está procurando aniquilar pela crítica imanente" (CoHn, 1979, p. 107).

Sobre isso, Otávio Velho oferece uma interpretação que reconduz a tentativa weberiana de fundamentar a legitimidade do conhecimento científico na senda da Filosofia nietzschiana. Segundo esse comentador, a operacionalização do método weberiano retornaria a relacionar-se com a perspectiva filosófica de Nietzsche por meio do caráter utilitário dos valores e das verdades, isto é, pelas vias do "pragmatismo" que habita a Filosofia nietzschiana. Nesse caso, os conceitos e as regras da causalidade, embora se constituam como "aparentes verdades", guardariam, ainda assim - e nisso reside seu valor -, a necessária utilidade para a manutenção da vida humana. Essa interpretação reenfatiza o aspecto operacional dos tipos ideais, isto é, instrumento para um tipo de conhecimento possível da realidade. Para Velho (1995, p. 83), trata-se de, "reconhecida a verdadeira natureza dos conceitos, utilizá-los como instrumento”.

\section{APREENSÃO DA MODERNIDADE}

Conforme assevera Otávio Velho (1995, p. 99), a "questão do Ocidente e sua especificidade" é o assunto central que transpassa toda a produção weberiana. Como bem observa o comentador, essa mesma questão é o núcleo em que gravita o conjunto das reflexões nietzschianas, o cerne mesmo de suas preocupações materializadas na vasta produção.

Desde seus primeiros escritos, portanto, já em $O$ nascimento da tragédia (1871), encontra-se a problemática sobre a especificidade do Ocidente e os frutos maduros de um processo de civilização que caracterizam a época moderna. Para Nietzsche, a problemática fundamental gravita sobre as disposições diante da vida contidas na "sabedoria teórica ou racional", representada pela figura de Sócrates como fundador dessa mentalidade. A característica específica desta "sabedoria racional", duramente e constantemente martelada por Nietzsche, está em sua posição de rejeição da vida, uma hostilidade para tudo aquilo que é natural.

No que se refere à proximidade de Weber e Nietzsche em torno da questão da racionalidade ocidental, assevera Velho (1995, p. 99) que estaríamos "em posição 
privilegiada para avaliar a complexidade, não só epistemológica e metodológica, mas, também, substantiva e filosófica, da comparação entre os dois, a qual incorpora e ultrapassa a esfera da influência”.

As questões relacionadas ao desenvolvimento do processo de racionalização no Ocidente aparecem tipificadas em Weber na forma do "desencantamento do mundo" e da perda do sentido da vida, experiências que caracterizariam o ambiente espiritual do mundo moderno. Na percepção dessa trajetória histórica do Ocidente que culmina com o advento do racionalismo ocidental moderno, Weber e Nietzsche aparentam-se. As características do "mundo desencantado" e racionalizado apresentado por Weber aproximam-se essencialmente das ideias nietzschianas sobre a "morte de Deus" e "niilismo", isto é, o processo de "desvalorização dos valores supremos". Exposições acerca de uma perda do sentido do mundo e dos valores supremos são compartilhadas por ambos os autores e estariam relacionadas com a escalada de um racionalismo tipicamente ocidental (europeu), cujo ápice projeta-se à modernidade.

Em Nietzsche, o alegórico anúncio da "morte de Deus" se apresenta como um signo para o estado do "niilismo". Por conseguinte, a época moderna vivenciaria a condição de perda do sentido da vida conferida pela força daqueles valores esfacelados. A experiência do "niilismo" figura no pensamento nietzschiano como a característica fundamental da atmosfera espiritual (moral-cultural) em que respira o mundo moderno.

Em Weber, a interpretação do esvaziamento de sentido do mundo experimentada na modernidade é emblematicamente demonstrada nos termos do "desencantamento do mundo". Nesse sentido, Weber teria recolocado o "problema da 'perda de sentido' e da 'morte de Deus' fundamentalmente pela idéia de desencantamento do mundo" (NoBre, 2003, p. 60). Segundo definição de Nobre, o desencantamento descrito por Weber designaria um duplo aspecto. Por um lado, representaria a "fragmentação das 'esferas culturais' devido aos processos históricos de racionalização". Por outro lado, refletiria a "expulsão dos valores superiores para o âmbito do misticismo ou das vivências mais íntimas devido à disseminação de procedimentos formais nas esferas mais cotidianas" (NoBRE, 2003, p. 60).

A "decadência" dos valores supremos que afeta a esfera espiritual do mundo moderno é acompanhada também de uma crise das instituições. Em Weber, a expressão da decadência nas instituições políticas modernas pode ser percebida sob os aspectos da burocratização - que é o efeito da racionalização ocidental na esfera institucional da política - e o amortecimento da vontade criadora de valores. De um lado, o desenvolvimento da burocracia se institucionalizara como 
sistema de "mediocridade" pela ascensão ao poder da burguesia. Sobre isso, Fleischmann retira de um pronunciamento de Weber o seguinte comentário: “A burguesia, 'os últimos homens que inventaram a felicidade' [...] inventou um meio para se conservar em vida: é a burocratização da vida social e da vida do Estado" (Fleischmann, 1977, p. 164).

A referência aos "últimos homens", acima transcrita, reporta-se diretamente a Nietzsche. Em uma das passagens contidas em Zaratustra, Nietzsche assim descreve o tipo "último-homem": "A terra tornar-se-á então mais pequena, e sobre ela andará aos pulos o último homem, que tudo apouca. A sua raça é indestrutível como a da pulga; o último homem é o que vive mais tempo" (Nietzsche, [s/d], p. 15). A alusão depreciativa ao tipo de vida burguês expresso segue ao longo do trecho.

A burocratização da vida social e política torna-se, assim, uma ameaça às possibilidades de criação dos novos valores. E é aqui nesse contexto que reaparece em Weber outra forte marca do pensamento nietzschiano, a tipologia psicossociológica da noção do "além-do-homem" [übermench]. O "além-do-homem" nietzschiano aparece, na obra de Weber transubstanciado na figura do "líder carismático", como sendo aquele que é capaz de enfrentar a crise dos valores e, de modo particular, confrontar o abatimento da força criadora provocada pela burocratização da vida política. Desse modo, e acompanhando Nietzsche, Weber também diagnosticaria a decadência da época como impotência para a construção de novos valores. Para Fleischmann (1977, p. 165), essa “opção por esse homem de poderosa vontade - e as razões que o levaram até esse ponto - que faz de Weber o executor testamentário de Nietzsche no domínio da política”.

Vê-se que, nesse ponto, Weber e Nietzsche compartilham também o diagnóstico de uma crise cultural da modernidade, no sentido de um enfraquecimento do potencial criativo de novos valores, de que seriam portadores os grandes indivíduos. Conforme indica Nobre (2003, p. 60), os dois autores "concebiam os tempos áureos como períodos de criação, e os criadores como grandes homens". No contexto cultural de crise, a decadência também se mostraria em condições "inóspitas ao aparecimento desses tipos extraordinários, quer porque impunham à especialização, quer porque enalteciam a opinião da maioria” (NoBRE, 2003, p. 60).

\section{POSTURA ÉTICA OU POSICIONAMENTO NO MUNDO}

Em um contexto sociocultural em que os valores supremos se esfacelam, em que o sentido do mundo se esvai, só restaria ao próprio indivíduo dotar seu mundo de significado e sentido. Referindo-se a uma passagem da carta endere- 
çada ao economista Robert Liefmann, em 1920, Cohn (1979, p. 102) comenta que não seria possível olvidar Nietzsche, quando Weber "enfatiza o caráter radicalmente destituído de sentido intrínseco do 'mundo' e que, portanto, compete aos próprios homens outorgarem significado a alguns entre os infinitos eventos que o constituem".

Tanto Weber quanto Nietzsche esboçaram um posicionamento diante do mundo em termos de resposta face ao diagnóstico do ambiente cultural da modernidade. Eis que o panorama descrito era de uma escalada na depreciação dos valores supremos, um mundo de significativa fuga dos sentidos; em suma, uma era de nülismo e desencantamento. É, portanto, na formulação de uma postura ética, isto é, no sentido de uma postura diante do mundo, que se revela mais um paralelo entre as considerações de Weber e Nietzsche. Outro importante traço comum destacável é que tal postura assume um caráter individual enquanto instância na qual se desenvolve a criação dos valores face ao niilismo e à perda do sentido do mundo da época moderna. A formulação de uma nova postura ética exigiria uma conduta "digna" e "coerente" em relação ao seu tempo, "à altura das 'verdades' trazidas com a crise dos valores superiores" (NoBRe, 2003, p. 62).

Na configuração dessa postura ética diante do mundo, dois atributos se encontram compartilhados por ambos os autores: o "realismo ético" e o "subjetivismo ético". Segundo Nobre (2003, p. 65), o "realismo ético" corresponde a uma "dose de resignação (ou pessimismo) contida em ambas as máximas, apontando ora para as forças racionais modeladoras de um mundo como destino (Weber) ora para as forças naturais modeladoras da vida como destino (Nietzsche)".

Quanto ao "subjetivismo ético", refletiria a "enorme dose de coragem na qual a dignidade se edifica na personalidade ou no espírito, como capacidade de agir com distanciamento e profundidade em relação às pessoas e às coisas" (NoBre, 2003, p. 65). O traço subjetivista da postura ética significa que o indivíduo é intimado, ele próprio, a responsabilizar-se pela criação dos novos valores. $\mathrm{O}$ "indivíduo é ‘convidado' a dar, ele próprio, sentido à sua presença no mundo” (NoBRE, 2003, p. 83). Em um contexto cultural marcado pelo esfacelamento dos valores supremos e pela perda do sentido do mundo, é o homem, em sua individualidade, convocado e encarregado de atribuir sentido à sua existência.

As características da postura ética prescritas por Weber e Nietzsche ainda apontam em comum para dois ataques fundamentais: um "anti-idealismo" e um "anti-universalismo". Assim, na configuração dessa postura diante do mundo e da vida, não há direcionamentos a uma instância abstrata, aos idealismos e universa- 
lismos com os presentes em doutrinas morais e metafísicas. É uma postura ética que exige respostas no nível particular e no concreto.

Para enfrentar as necessidades do tempo histórico, ambos apostam na "emergência de um espírito que possa encarar de frente (sic) a sua época e, nela, dar conta de sua tarefa ou de sua obra" (NoBRe, 2003, p. 65-6). Dessa forma, no caráter individual exigido por essa ética, transparece a marca virtuose e aristocrática da proposta, em que honra, bravura e coragem seriam atributos necessários para armar o espírito individual de força suficiente para erigir seus valores.

Nas possibilidades de enfrentamento dos processos históricos que arrastam a todos à "jaula de ferro", Otávio Velho (1995, p. 105) faz notar que a noção de "carisma" em Weber representaria, em "nossa sociedade, o antagonista histórico da racionalização". Nesse sentido, o carisma simboliza essa postura ética exigida, constituindo-se enquanto antagonista diante de um mundo cada vez mais submetido ao processo de racionalização, fragmentação e perda de seu sentido.

$\mathrm{O}$ carisma pensado por Weber repousaria em uma atitude face ao mundo moderno, a qual em muito se aparenta com os atributos do "além-do-homem" nietzschiano. Ambos miram formações socioculturais que manifestam o esvaziamento do sentido do mundo. O carisma "deveria se opor, embora paradoxalmente, às estruturas desencantadas e sem espírito da racionalidade burocrática extremada, tal como o sobre-homem se opõe ao niilismo em todas as suas formas" (VELHo, 1995, p. 105).

Ainda no que se refere à atitude diante da modernidade, Velho (1995, p. 103-104) aponta que Weber e Nietzsche compartilharam também a própria visão do processo histórico, ressalvando, no entanto, que variaram "na atitude diante dele". Enquanto Weber visava armar o "espírito à altura do seu tempo e de suas significações fragmentadas", Nietzsche "desejava o espírito à altura da vida e precisamente contra tais significações” (NoBRE, 2003, p. 74). Haveria, portanto, uma diferença fundamental na direção em que as posturas éticas se inclinam. Tais diferenças corresponderiam, fundamentalmente, há um leitmotiv racionalista (Weber) e a outro vitalista (Nietzsche), de maneira que os autores "localizaram as ações do espírito digno em 'disposições' distintas: num caso, o ethos da consciência reflexiva, no outro, o pathos da sensibilidade artística” (NoBre, 2003, p. 74). Aqui, a diferença fundamental entre ethos (ética) e pathos (sentimento) é que, enquanto Weber se refere à cultivação racional do caráter, Nietzsche dá atenção aos impulsos não racionais na construção do caráter individual.

A marca da diferença estaria em que, enquanto a postura ética vislumbrada por Weber se apresenta em uma forma de resignação perante o desenrolar dos 
acontecimentos inerentes ao processo de racionalização, em Nietzsche a prescrição de uma conduta diante da vida inclinar-se-ia para uma reviravolta dos valores, que se encontrariam já desgastados pelos acontecimentos em curso. Conforme constata Nobre (2003, p. 74-75), haveria aqui a tensão entre uma "postura ética centrada no ideal de 'inserção' crítica nas condições objetivas (responsabilidade)" e outra "centrada no ideal da 'transvaloração' dos valores (extemporaneidade)".

\section{CONSIDERAÇÕES FINAIS}

Abordar a recepção weberiana das ideias de Nietzsche se reveste de especial interesse para o ensino da teoria social, no sentido de identificar as ligações e afinidades teóricas daquele clássico da Sociologia com relação a um pensador não menos impactante no cenário intelectual da modernidade, como Nietzsche, cuja área de influência recobre vários campos culturais. Nesse sentido, o próprio Weber fez menção sobre a importância de considerar seu trabalho intelectual à luz das obras de Nietzsche e Marx.

Na esteira deixada pela literatura especializada acerca das proximidades entre a Sociologia de Max Weber e a Filosofia de Nietzsche, foi possível, na exploração aqui realizada, observar a recorrência com que se aponta a existência de alguns traços comuns presentes em temas de especial importância na obra de ambos os autores. Foi possível destacar, assim, relevos no terreno de considerações sobre a relação entre os dois autores. Esse foi o caso dos tópicos sobre as relações de poder e o caráter agonístico da existência, que transpassa a obra de ambos os autores; das considerações epistemológicas, em que se assume a perspectiva de certa arbitrariedade do conhecimento em relação à complexidade do mundo; da apreensão quanto à crise dos valores supremos (niilismo) e à perda do sentido do mundo (desencantamento) no que se refere ao ambiente cultural da modernidade; e da postura necessária diante desse mundo moderno, que é fortemente marcada por um realismo e subjetivismo ético.

No decurso desta pesquisa bibliográfica, foi possível observar que o elo fundamental que liga o pensamento de Weber à Filosofia nietzschiana é a questão dos valores culturais. Aqui se articulam todos os quatro eixos estruturantes expostos. É a questão dos valores que fará com que Weber reflita sobre os conflitos e as divergências no seio da vida social, construa sua metodologia e o alcance do conhecimento científico e, por fim, formule o diagnóstico do "desencantamento do mundo" e a resposta individual a este mundo moderno. 
Ambos os autores veem no processo sociocultural em curso, de amplas e profundas mutações no contexto alemão, a implicação de uma crise dos valores culturais. Aqui a personalidade individual, que se encontra para eles sob ataque diante de valores que induzem ao nivelamento e à homogeneização cultural, seja por meio da democracia e do socialismo, seja pela via da burocratização da vida social, é também de onde se pode encontrar a fonte em que se alicerçam as possibilidades de enfrentamento da crise cultural, resistência que será feita por meio do erigir de novos valores que possam ultrapassar o niilismo e o desencantamento do mundo, vivenciados em seu ápice no estágio moderno da civilização ocidental. Toda a questão do ambiente cultural remete aos valores e ao poder, força em estabelecer tais valores em um contexto de lutas e embate de perspectivas.

Se Nietzsche como filósofo e fora das amarras acadêmicas pode vivenciar uma maior liberdade de espírito, Weber como acadêmico e cientista tem de se mover dentro de um universo que o prende a certos procedimentos que são também alvo da crítica nietzschiana. Mesmo assim, Weber assume a parcialidade e precariedade do conhecimento produzido pela ciência, e é no terreno da política que o cientista deposita maiores expectativas na criação dos novos valores-chave de entendimento para a compreensão do líder carismático que irrompe contra a ordem burocrática. Mesmo advogando no trabalho científico, uma separação entre juízos de valor e juízo de fato perpassa ao fundo do pensamento weberiano, e é visivelmente expresso em muitas de suas manifestações públicas, como uma tensão que oscila, ainda que de modo contido, entre a crítica embasada no posicionamento valorativo e a resignação diante dos fatos e acontecimentos históricos. Como indicação sugestiva, deixe-se que a passagem a seguir, contida nos parágrafos finais de Ética protestante, em relação ao qual se pensa as consequências do processo de racionalização ocidental, testemunhe o tom dessa tensão insinuada - sem, contudo desfazer o projeto metodológico de Weber.

Ninguém sabe ainda quem no futuro vai viver sob essa crosta e, se ao cabo desse desenvolvimento monstro hão de surgir profetas inteiramente novos, ou um vigoroso renascer de velhas idéias e antigos ideais, ou - se nem uma coisa nem outra - o que vai restar não será uma petrificação mecanizada, arrematada com uma espécie convulsiva de auto-suficiência. Então, para os "últimos homens" desse desenvolvimento cultural, bem poderia tornar-se verdade as palavras: "Especialistas sem espírito, gozadores sem coração: esse Nada imagina ter chegado a um grau de humanidade nunca antes alcançado" (WEBER, 2004, p. 166). 


\section{REFERÊNCIAS BIBLIOGRÁFICAS}

Cohn, Gabriel. Weber, Nietzsche e a crítica dos valores. In: Coнn, Gabriel. Crítica e resignação. São Paulo: T.A. Queiroz, 1979.

Fleischmann, Eugène. Weber e Nietzsche. In: Cohn, Gabriel (Org.). Sociologia: para ler os clássicos. Rio de Janeiro: Livros Técnicos e Científicos, 1977.

Hennis, Wilhelm. Les traces de Nietzsche dans l'oeuvre de Max Weber. In: Hennis, Wilhelm. La problematique de Max Weber. Paris: Presses Universitaires de France, 1986. p. 181-206.

NietzSche, Friedrich W. Genealogia da moral: uma polêmica. São Paulo: Companhia das Letras, 1998.

A vontade de poder. Rio de Janeiro: Contraponto, 2008. . Assim falava Zaratustra. São Paulo: Formar, [s/d].

NoBRE, Renarde Freire. Weber, Nietzsche e as respostas éticas à crítica da modernidade. Trans/Form/Ação, v. 26, n. 1, p. 53-86, 2003.

Três teses comparativas entre os pensamentos de Weber e de Nietzsche. Rev. bras. Ci. Soc., v. 19, n. 56, p. 29-43, Out. 2004.

ÖElze, Berthold. Weber e Nietzsche. In: SouzA, Jessé (Org.). A atualidade de Max Weber. Brasília: UNB, 2000. p. 261-275.

VelHo, Otávio. Considerações (in)tempestivas sobre Nietzsche e Weber. In: VelHo, Otávio.

Besta-fera: recriação do mundo - ensaios críticos de antropologia. Rio de Janeiro: Relume-Dumará, 1995. p. 77-115.

Weber, Max. A psicologia social das religiões mundiais. In: Weber, Max. Ensaios de Sociologia. 5. ed. Rio de Janeiro: Guanabara, 1982.

. A ética protestante e o "espírito" do capitalismo. São Paulo: Companhia das Letras, 2004.

Recebido para publicação em 07/05/2013. Aceito para publicação em 05/11/2013. 
